\title{
PENGGUNAAN METODE MIND MAPING UNTUK MENINGKATKAN PEMBELAJARAN IPS PADA SISWA KELAS VIII B SEMESTER II SMP NEGERI 1 BOJ ONGGENTENG TAHUN PELAJ ARAN 2017/2018"
}

\author{
NINA GANTINA KUSTIAN \\ SMP Negeri 1 Bojonggenteng Sukabumi Jawa Barat \\ ninakustian.g28@gmail.com
}

\begin{abstract}
ABSTRAK
Penelitian ini bertujuan untuk meningkatkan meningkatkan kemampuan mengemukakan pendapat pada siswa kelas VIII B SMPN 1 Bojonggenteng tahun Pelajaran 2017/2108 dengan menggunakan metode Mind Mapping. Metode penelitian ini adalah PTK (Penelitian Tindakan Kelas). Populasi penelitian adalah seluruh siswa kelas VIII B SMPN 1 Bojonggenteng Tahun Pelajaran 2017/2018. Kemampuan mengemukakan pendapat siswa kelas VIII B SMPN I Bojonggenteng tahun pelajaran 2017/2018 mengalami peningkatan. Peningkatan yang cukup tinggi dicapai oleh siswa bernama Suhendi. Pada siklus I siswa tersebut hanya mendapat nilai 4 sedangkan pada siklus II mendapat nilai 8, dengan demikian presentase yang dicapai siswa tersebut adalah $100 \%$. Sedangkan peningkatan paling rendah ditunjukkan oleh siswa yang bernama Agus Setiawan, pada siklus I siswa tersebut mendapat nilai 11 sedangkan pada siklus II mendapat nilai 12. Dengan demikian siswa tersebut mendapat presentase kenaikan sebesar 9\%.Dengan memperhatikan tentang kinerja siswa maka kemampuan mengemukakan pendapat pada siswa kelas VIII B SMPN I Bojonggenteng tahun pelajaran 2017/2018 semester II terjadi peningkatan 44,15\%.Peningkatan itu terlihat pada waktu siklus II diadakan yaitu siswa menjawab dan mengajukan pendapat lebih tenang, suaranya dapat terdengar, lebih berani, tidak takut salah, tidak grogi, tidak takut ditertawakan teman dan lebih percaya diri dalam menjawa pertanyaan atau mengemukakan pendapatnya.Dari data tersebut maka dapat disimpulkan bahwa "Jika siswa diajak belajar IPS dengan menggunakan model pembelajaran Mind Mapping maka kemampuan mengeluarkan pendapat akan meningkat".
\end{abstract}

Kata Kunci: Mind Mapping, Kemampuan Pendapat, Pengetahun

\section{PENDAHULUAN}

Mata pelajaran IPS sebagai salah satu mata pelajaran yang sangat penting untuk dikuasai siswa. Saat ini, paradigma pendidikan telah berubah menuntut ukuran yang berbeda terhadap keberhasilan siswa dalam mata pelajaran IPS. Dimaksudkan, bila dalam kurikulum 1994, ukuran keberhasilan siswa lebih banyak pada segi kognitifnya, saat ini criteria keberhasilan siswa dalam mata pelajaran IPS dituntut untuk menanamkan nilai atau norma dalam kehidupan bermasyarakat. Salah satunya adalah kemampuan siswa untuk mengeluarkan pendapat tentang suatu permasalahan. Hal ini juga dialami peneliti saat melakukan kegiatan belajar mengajar di kelas VIII B, terutama untuk kemampuan mengemukakan pendapat, sangat sulit meminta siswa untuk mengungkapkan pikiran, perasaan dan informasi baik dalam kegiatan tanya jawab maupun dalam kegiatan diskusi. Hanya 25\% siswa yang mempunyai 
kemampuan mengeluarkan pendapat. Peneliti berbicara di depan kelas saat pembelajaran IPS berlangsung.

Kesulitan ini menurut kesimpulan peneliti dikarenakan mereka tidak terbiasa berbicara di kelompok dan di depan kelas. Seandainya mereka dimotivasi dan dibiasakan untuk berbicara, maka kemungkinan siswa tidak akan mengalami kesulitan lagi untuk berbicara di kelompok dan di depan kelas. Untuk motivasi dan membiasakan siswa berbicara di kelompok dan di depan kelas, menurut peneliti dapat dilakukan dengan menggunakan model pembelajaran Mind Mapping. Hal ini disebabkan pada model pembelajaran ini, setiap siswa diberi kesempatan dan dilatih mengemukakan pendapat dikelompoknya serta untuk menanggapi permasalahan yang diberikan guru kepada kelompoknya. Jika sudah terbiasa mengemukakan pendapat dikelompoknya, maka siswa kemungkinan tidak akan mengalami hambatan mengemukakan pendapat di depan kelas.

Hal inilah yang mendasari peneliti untuk melakukan Penelitian Tindakan Kelas (PTK) pada siswa kelas VIII B SMP Negeri 1 Bojonggenteng, dengan judul: "Penggunaan metode mind maping untuk meningkatkan pembelajaran IPS pada siswa VII B semester II SMP Negeri 1 Bojonggenteng tahun pelajararan 2017/2018".

Berdasarkan latar belakang yang telah dikemukakan di atas, masalah yang akan dibahas dalam Penelitian Tindakan Kelas ini dirumuskan sebagai berikut:"Apakah penggunaan model pembelajaran Mind Mappimg dapat meningkatkan kemampuan mengemukakan pendapat pada mata pelajaran IPS bagi siswa kelas VIII B SMP NEG ERI I Bojonggenteng semester II Tahun Pembelajaran 2017/2018".

\section{METODE PENELITIAN}

Metode penelitian ini adalah PTK (Penelitian Tindakan Kelas). Penelitian ini menggunakan 2 siklus yang setiap siklus terdiri dari satu kali pertemuan. Tahapan pada setiap siklus yaitu tahap perencanaan, pelaksanaan tindakan, pengamatan dan refleksi. Populasi penelitian ini mengguankan siswa kelas VIII SMPN 1 Bojonggenten Tahun Pelajaran 2017/2018. Subjek penelitian ini yaitu siswa kelas VIII-B SMPN1 Bojonggenteng Tahun Pelajaran 2017/2018 yang berjumlah 40 siswa yang terdiri dari 20 siswa putra dan 20 siswa putri.

\section{HASIL DAN PEMBAHASAN}

Hasil Penelitian Tindakan Kelas yang berjudul Meningkatkan kemampuan mengemukakan pendapat pada mata pelajaran IPS melalui model pembelajaran Mind Mapping [kasus pada siswa kelas VIII B semester II SMP Negeri 1 Bojonggenteng ], dapat diambil dari hasil observasi kinerja siswa pada siklus I yang telah direfleksi serta diberikan tindakan tindakan pada aspek yang belum mencapai katrgori baik, maka diperoleh hasil analisis yang ditampilkan pada table berikut: 


\begin{tabular}{|l|l|l|l|l|}
\hline No & Aspek yang diamati siswa dalam & Siklus 1 & Siklus II & Keterangan \\
\hline a. & $\begin{array}{l}\text { Ketepatan bunyi-bunyi } \\
\text { mengucapkan } \\
\text { [vocal,konsonan] }\end{array}$ & $\begin{array}{l}\text { Kurang } \\
\text { lancar } \\
\text { Cukup } \\
\text { lancar }\end{array}$ & meningkat \\
\hline b. & $\begin{array}{l}\text { Ketepatan siswa dalam intonasi, } \\
\text { naik turunna suara serta } \\
\text { tekanan suku kata }\end{array}$ & $\begin{array}{l}\text { Kurang } \\
\text { lancar } \\
\text { kata-kata yang diucapkan }\end{array}$ & $\begin{array}{l}\text { Cukup } \\
\text { lancar }\end{array}$ & meningkat \\
\hline c. & $\begin{array}{l}\text { Ketepatan bentuk dan urutan } \\
\text { Kurang } \\
\text { lancar }\end{array}$ & $\begin{array}{l}\text { Cukup } \\
\text { lancar }\end{array}$ & Meningkat \\
\hline d. & $\begin{array}{l}\text { Kewajaran / kelancaran siswa } \\
\text { dalam berbicara }\end{array}$ & $\begin{array}{l}\text { Kurang } \\
\text { lancar } \\
\text { lancar }\end{array}$ & Meningkat \\
\hline
\end{tabular}

Berdasarkan analisis hasil observasi pada saat proses belajar mengajar berlangsung dapat dilihat pada table observasi berikut:

Tabel 2. Observasi Siswa

\begin{tabular}{|l|l|l|l|l|l|l|l|l|l|l|}
\hline \multirow{2}{*}{ No } & \multirow{6}{*}{ Nama Siswa } & \multicolumn{6}{|c|}{ Aspek yang diamati } & \multirow{2}{*}{ Keterangan } \\
\cline { 3 - 10 } & & \multicolumn{5}{|c|}{ Siklus 1 } & \multicolumn{5}{c|}{ Siklus 2 } \\
\cline { 2 - 9 } & A & B & C & D & A & B & C & D & \\
\hline 1 & ACEP RIZKI M & 3 & 2 & 3 & 3 & 3 & 3 & 4 & 3 & Meningkat \\
\hline 2 & AGUNG GUNAWAN & 2 & 1 & 2 & 2 & 3 & 2 & 3 & 3 & Meningkat \\
\hline 3 & AHMAD KAMAL & 2 & 1 & 2 & 2 & 3 & 2 & 3 & 3 & Meningkat \\
\hline 4 & ANDRIANSYAH & 1 & 1 & 1 & 2 & 2 & 2 & 2 & 3 & Meningkat \\
\hline 5 & ANGGA & 1 & 1 & 1 & 1 & 2 & 2 & 2 & 2 & Meningkat \\
\hline 6 & ARISANDI & 3 & 2 & 3 & 3 & 3 & 4 & 4 & 4 & Meningkat \\
\hline 7 & DERI PERMANA & 3 & 2 & 3 & 3 & 3 & 3 & 4 & 4 & Meningkat \\
\hline 8 & DINDA SELIMAUDI & 2 & 2 & 2 & 2 & 3 & 3 & 3 & 3 & Meningkat \\
\hline
\end{tabular}




\begin{tabular}{|c|c|c|c|c|c|c|c|c|c|c|}
\hline 9 & $\begin{array}{l}\text { DWI RAHAYU } \\
\text { NINGSIH }\end{array}$ & 3 & 3 & 3 & 3 & 4 & 4 & 4 & 4 & Meningkat \\
\hline 10 & ELSA OKTAVIANI & 2 & 2 & 2 & 2 & 3 & 2 & 3 & 3 & Meningkat \\
\hline 11 & ELSA RIANTIKA & 3 & 2 & 3 & 3 & 4 & 3 & 4 & 4 & Meningkat \\
\hline 12 & ENDANG P & 2 & 1 & 2 & 2 & 3 & 2 & 3 & 3 & Meningkat \\
\hline 13 & FITRIANA KUSUMA & 2 & 1 & 2 & 2 & 2 & 2 & 3 & 3 & Meningkat \\
\hline 14 & GINA SONIA & 1 & 1 & 2 & 2 & 2 & 2 & 3 & 3 & Meningkat \\
\hline 15 & HERDIN F & 1 & 1 & 2 & 2 & 2 & 2 & 3 & 3 & Meningkat \\
\hline 16 & IFAN RIFALDI & 1 & 1 & 2 & 2 & 3 & 2 & 2 & 3 & Meningkat \\
\hline 17 & INTAN NADIA & 1 & 1 & 2 & 2 & 2 & 2 & 2 & 3 & Meningkat \\
\hline 18 & LUKI PARLI & 1 & 1 & 2 & 2 & 2 & 1 & 3 & 2 & Meningkat \\
\hline 19 & MUH. ARIA RUSLAN & 2 & 2 & 3 & 2 & 2 & 2 & 3 & 3 & Meningkat \\
\hline 20 & MUH. FARHAN S & 3 & 2 & 3 & 3 & 4 & 3 & 3 & 3 & Meningkat \\
\hline 21 & MUHAMMAD SY & 2 & 2 & 2 & 3 & 3 & 2 & 3 & 3 & Meningkat \\
\hline 22 & NOVITA SARI & 2 & 1 & 2 & 2 & 3 & 2 & 2 & 2 & Meningkat \\
\hline 23 & RATNA & 2 & 1 & 3 & 2 & 2 & 2 & 4 & 2 & Meningkat \\
\hline 24 & RESTI & 1 & 1 & 3 & 2 & 2 & 2 & 4 & 3 & Meningkat \\
\hline 25 & RIAN HERMAWAN & 1 & 1 & 3 & 2 & 2 & 2 & 2 & 2 & Meningkat \\
\hline 26 & SINTA ANDRIANI & 2 & 2 & 3 & 2 & 2 & 3 & 4 & 3 & Meningkat \\
\hline 27 & SINTA BELLA & 1 & 1 & 2 & 2 & 2 & 3 & 3 & 2 & Meningkat \\
\hline 28 & SULFAH NOER A & 1 & 1 & 2 & 2 & 2 & 3 & 3 & 2 & Meningkat \\
\hline 29 & UCUP SUPRIATNA & 1 & 2 & 3 & 2 & 3 & 3 & 4 & 3 & Meningkat \\
\hline 30 & YUDI WAHYUDI & 3 & 2 & 3 & 2 & 4 & 3 & 4 & 3 & Meningkat \\
\hline 31 & YUNI FAJARESTIANI & 2 & 2 & 3 & 2 & 3 & 3 & 4 & 3 & Meningkat \\
\hline 32 & SITI AWALIYAH & 2 & 2 & 3 & 2 & 3 & 2 & 4 & 3 & Meningkat \\
\hline 33 & SITI NURJANAH & 2 & 2 & 3 & 2 & 3 & 4 & 4 & 4 & Meningkat \\
\hline
\end{tabular}




\begin{tabular}{|c|c|c|c|c|c|c|c|c|c|c|}
\hline 34 & SITI SA'DIAH & 4 & 3 & 3 & 3 & 5 & 4 & 4 & 4 & Meningkat \\
\hline 35 & SINDY MOELIDIYA & 3 & 3 & 3 & 3 & 3 & 3 & 4 & 4 & Meningkat \\
\hline 36 & SELLA MARSELINA & 2 & 2 & 2 & 3 & 3 & 3 & 3 & 4 & Meningkat \\
\hline 37 & SISKA AMELIA & 3 & 2 & 2 & 2 & 4 & 2 & 3 & 3 & Meningkat \\
\hline 38 & TAUFIK DIDAYAT & 2 & 1 & 2 & 2 & 3 & 2 & 2 & 3 & Meningkat \\
\hline 39 & SOPYAN SAURI & 2 & 1 & 2 & 2 & 3 & 2 & 2 & 3 & Meningkat \\
\hline 40 & ZAIDAN FAKHRI S & 2 & 1 & 2 & 2 & 3 & 2 & 3 & 2 & Meningkat \\
\hline & $\begin{array}{l}\text { Jumlah nilai } 1 \\
\text { Jumlah nilai } 2 \\
\text { Jumlah nilai } 3 \\
\text { Jumlah nilai } 4 \\
\text { Jumlah nilai } 5\end{array}$ & $\begin{array}{l}12 \\
18 \\
9 \\
1 \\
0\end{array}$ & $\begin{array}{l}13 \\
14 \\
3 \\
0 \\
0\end{array}$ & $\begin{array}{l}2 \\
21 \\
17 \\
0 \\
0\end{array}$ & $\begin{array}{l}2 \\
29 \\
10 \\
0 \\
0\end{array}$ & $\begin{array}{l}1 \\
14 \\
0 \\
0 \\
0\end{array}$ & $\begin{array}{l}1 \\
24 \\
11 \\
4 \\
0\end{array}$ & $\begin{array}{l}0 \\
7 \\
19 \\
14 \\
0\end{array}$ & $\begin{array}{l}0 \\
6 \\
2 \\
7 \\
7 \\
0\end{array}$ & Meningkat \\
\hline & Jumlah & 40 & 40 & 40 & 40 & 40 & 40 & 40 & $\begin{array}{l}4 \\
0\end{array}$ & Meningkat \\
\hline
\end{tabular}

Keterangan huruf: (A) Ketepatan siswa dalam mengucapkan bunyi-bunyi tertentu (vocal, konsonan). (B) Ketepatan siswa dalam intonasi, naik turunnya suara serta tekanan suku kata. (C) Ketepatan bentuk dan urutan kata-kata yang diucapkan (D) Kewajaran atau kelancaran siswa dalam berbicara

Keterangan angka/nilai: (a) Nilai 5 berarti sangat tepat/sangat wajar/sangat lancar. (b) Nilai 4 berarti tepat/wajar/lancar. (c) Nilai 3 berarti cukup tepat/cukup lancar/ cukup wajar. (d) Nilai 2 berarti kurang tepat/kurang lancar/kurang wajar. (e) Nilai 1 berarti tidak tepat/tidak lancar/tidak wajar

\section{PEMBAHASAN}

Pembahasan Siklus I Aspek ketepatan siswa dalam mengucapkan bunyi-bunyi tersendiri (vocal, konsonan), rata-rata kurang lancar, hal ini terlihat dari cara penyampaian siswa belum terbiasa mengemukakan pendapat, masih banyak yang diam tidak memberikan komentar terhadap masalah yang sedang dibahas dalam kelompoknya.

Aspek ketepatan siswa dalam intonasi, naik turunnya suara serta tekanan suku kata rata-rata kurang lancar, hal ini terlihat pada waktu siswa menjawab pertanyaan/mengemukakan pendapat dengan suara yang rendah atau hamper tidak terdengar. Aspek ketepatan bentuk dan urutan kata-kata yang diucapkan siswa rata-rata 
kurang lancar, hal ini terlihat pada waktu menjawab pertanyaan/mengemukakan pendapat ragu-ragu, takut salah dan takut ditertawakan teman.

Aspek kewajaran/kelancaran siswa dalam berbicara rata-rata juga kurang lancar, hal ini terlihat pada waktu siswa menjawab pertanyaan/mengemukakan pendapat dengan rasa malu dan grogi. Dengan demikian kemampuan mengemukakan pendapat siswa kelas VIII B SMP Negeri I Bojonggenteng semester II tahun pelajaran 2017/2018 pada siklus I rata rata kurang lancer, hal itu ditandai dengan belum terbiasa mengeluarkan pendapat, menjawab pertanyaan dengan suara rendah hampir tidak terdengar ragu ragu, takut salah, takut ditertawakan, malu dan grogi.

Setelah melakukan evaluasi, analisis dan diskusi dengan observer maka diperoleh kesimpulan bahwa ada beberapa langkah pembelajaran yang diperbaiki untuk tahap berikutnya yaitu (1) Harus lebih memberikan motivasi, baik secara intrinsic maupun secara ekstrinsik agar siswa mau belajar mengemukakan pendapat, misalnya ; bagi siswa yang berani mengemukakan pendapat diberi nilai, hadiah atau reward lainnya. (2) Mengajukan pertanyaan yang mengandung banyak alternate jawaban / pertanyaan tingkat tinggi. (3) Memberikan kesempatan kepada siswa yang belum berani mengemukakan pendapatdengan memanggil namanya. (4) Berikan motivasi membaca buku pelajaran untuk pertemuan berikutnya. Dari hasil refleksi, temuan-temuan dan kekurangan-kekurangan yang terjadi pada siklus I akan dijadikan evaluasi untuk siklus berikutnya.

Pembahasan Siklus II, Kinerja siswa dalam pembelajaran baik, hal ini terlihat dari aspek yang diamati mengalami peningkatan dari siklus I. Ketepatan siswa dalam mengucapkan bunyi-bunyi tersendiri (vocal, konsonan) meningkat, hal itu terlihat pada waktu menjawab pertanyaan/mengemukakan pendapat lebih tenang.

Aspek ketepatan siswa dalam intonasi, naik dan turunnya suara serta tekanan suku kata, mengalami peningkatan, hal itu terlihat pada waktu siswa menjawab pertanyaan/mengemukakan pendapat suaranya dapat terdengar. Demikian pula aspek ketepatan bentuk dan urutan kata-kata yang diucapkan siswa mengalami peningkatan, hal ini terlihat pada waktu siswa menjawab pertanyaan/mengemukakan pendapat lebih berani dan tidak takut salah mengemukakan pendapatnya.

Aspek yang berikutnya yaitu kewajaran/kelancaran siswa dalam berbicara mengalami peningkatan pula, hal ini terlihat pada waktu siswa menjawab pertanyaan/mengemukakan pendapat lebih tenang, tidak grogi dan lebih percaya diri. Kemampuan mengemukakan pendapat siswa kelas VIII B SMPN I Bojonggenteng tahun pelajaran 2017/2018 mengalami peningkatan. Peningkatan yang cukup tinggi dicapai oleh siswa bernama Suhendi.. Pada siklus I siswa tersebut hanya mendapat nilai 4 sedangkan pada siklus II mendapat nilai 8 , dengan demikian presentase yang dicapai siswa tersebut adalah $100 \%$. Sedangkan peningkatan paling rendah ditunjukkan oleh siswa yang bernama Agus Setiawan, pada siklus I siswa tersebut mendapat nilai 11 sedangkan pada siklus II mendapat nilai 12. Dengan demikian siswa tersebut mendapat presentase kenaikan sebesar $9 \%$.

Dengan memperhatikan tentang kinerja siswa maka kemampuan mengemukakan pendapat pada siswa kelas VIII B SMPN I Bojonggenteng tahun pelajaran 2017/2018 semester II terjadi peningkatan 44,15\%. Peningkatan itu terlihat pada waktu siklus II diadakan yaitu siswa menjawab dan mengajukan pendapat lebih tenang, suaranya dapat 
terdengar, lebih berani, tidak takut salah, tidak grogi, tidak takut ditertawakan teman dan lebih percaya diri dalam menjawa pertanyaan atau mengemukakan pendapatnya. Dari data tersebut maka dapat disimpulkan bahwa "Jika siswa diajak belajar IPS dengan menggunakan model pembelajaran Mind Mapping maka kemampuan mengeluarkan pendapat akan meningkat".

\section{KESIMPULAN DAN SARAN}

Kemampuan mengemukakan pendapat ada peningkatan hal itu terlihat pada waktu siklus II diadakan yaitu lebih tenang, suaranya dapat terdengar, lebih percaya diri dalam menjawab pertanyaan/mengemukakan pendapatnya. Kinerja siswa dalam pembelajaran menggunakan metode Mind Mapping akan berhasil jika: (a) Diberi kesempatan untuk menjawab/mengemukakan pendapat baik di dalam kelompoknya maupun di depan kelas. (b) Berikan motivasi, baik secara intrinsic maupun secara eksrinsik agar siswa mau belajar mengemukakan pendapat misalnya dengan memberikan nilai, hadiah atau reward lainnya. (c) Ajukan pertanyaan yang mengandung banyak alternatif jawaban/pertanyaan tingkat tinggi. (d) Beri kesempatan pada siswa yang belum berani mengemukakan pendapat

\section{DAFTAR PUSTAKA}

Abu, A dan Tri Prasetya, J.(1997). Strategi Belajar Mengajar. Bandung: Pustaka Setia. Ali, M. (1993). Strategi Belajar Mengajar. Bandung: Angkasa Depdiknas, 2008. Lesson Study, Citra diri, Penelitian Tindakan Kelas. Jakarta: Depdiknas.

Arikunto, Suharsimi. Suhardjono, dan Supardi. Penelitian Tindakan Kelas. Jakarta: Bumi Aksara

Bolla, J. I (1985). Keterampilan Bertanya Dasar dan Lanjut. Jakarta: CV Fortuna.

Dahar, R. W. (1989). Teori-teori Belajar. Jakarta: Erlangga

Depdiknas. 2007. Pedoman Blockgrant. Penelitian Tindakan Kelas. Jakarta : Depdiknas.

H. Rahman. Penelitian Tindakan Kelas.Depdiknas Pasca Sarjana UPI . Bandung: 2008

Hilda Karli dan Margaretha S.Y. 2004. Implementasi Kurikulum Berbasis Kompetensi. Model-model Pembelajaran. Jakarta: Bina Media Informasi

R. Ibrahim dan Nana Syaodih S. 1991. Perencanaan Pengajaran. Jakarta : Departemen P dan K, Rineka Cipta

Slameto. 2002. Belajar dan Faktor-faktor yang mempengaruhinya. Edisi Revisi. Jakarta: Rineka Cipta.

Suyanto, 1997. Pedoman Penelitian Tindakan Kelas (PTK). Jakarta: BP3SD, Dirjen Dikti, Depdikbud. 